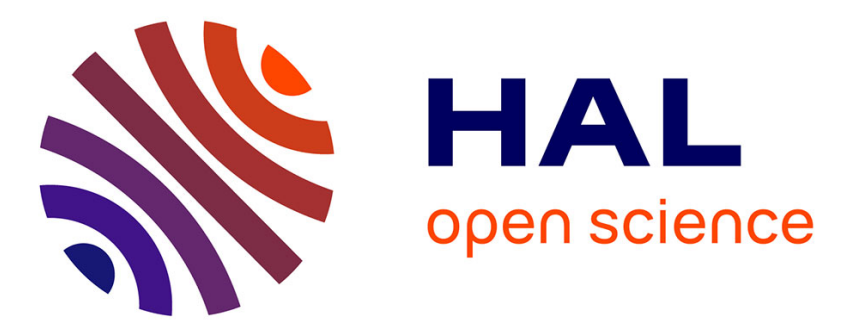

\title{
Risedronate and alendronate suppress osteocyte apoptosis following cyclic fatigue loading.
}

Hélène Follet, Jiliang Li, Roger J. Phipps, Siu Hui, Keith Condon, David B. Burr

\section{- To cite this version:}

Hélène Follet, Jiliang Li, Roger J. Phipps, Siu Hui, Keith Condon, et al.. Risedronate and alendronate suppress osteocyte apoptosis following cyclic fatigue loading.. BONE, 2007, 40 (4), pp.1172-7. 10.1016/j.bone.2006.12.052 . inserm-00557225

\section{HAL Id: inserm-00557225 https://www.hal.inserm.fr/inserm-00557225}

Submitted on 15 Jun 2011

HAL is a multi-disciplinary open access archive for the deposit and dissemination of scientific research documents, whether they are published or not. The documents may come from teaching and research institutions in France or abroad, or from public or private research centers.
L'archive ouverte pluridisciplinaire HAL, est destinée au dépôt et à la diffusion de documents scientifiques de niveau recherche, publiés ou non, émanant des établissements d'enseignement et de recherche français ou étrangers, des laboratoires publics ou privés. 
Provided for non-commercial research and educational use only. Not for reproduction or distribution or commercial use.
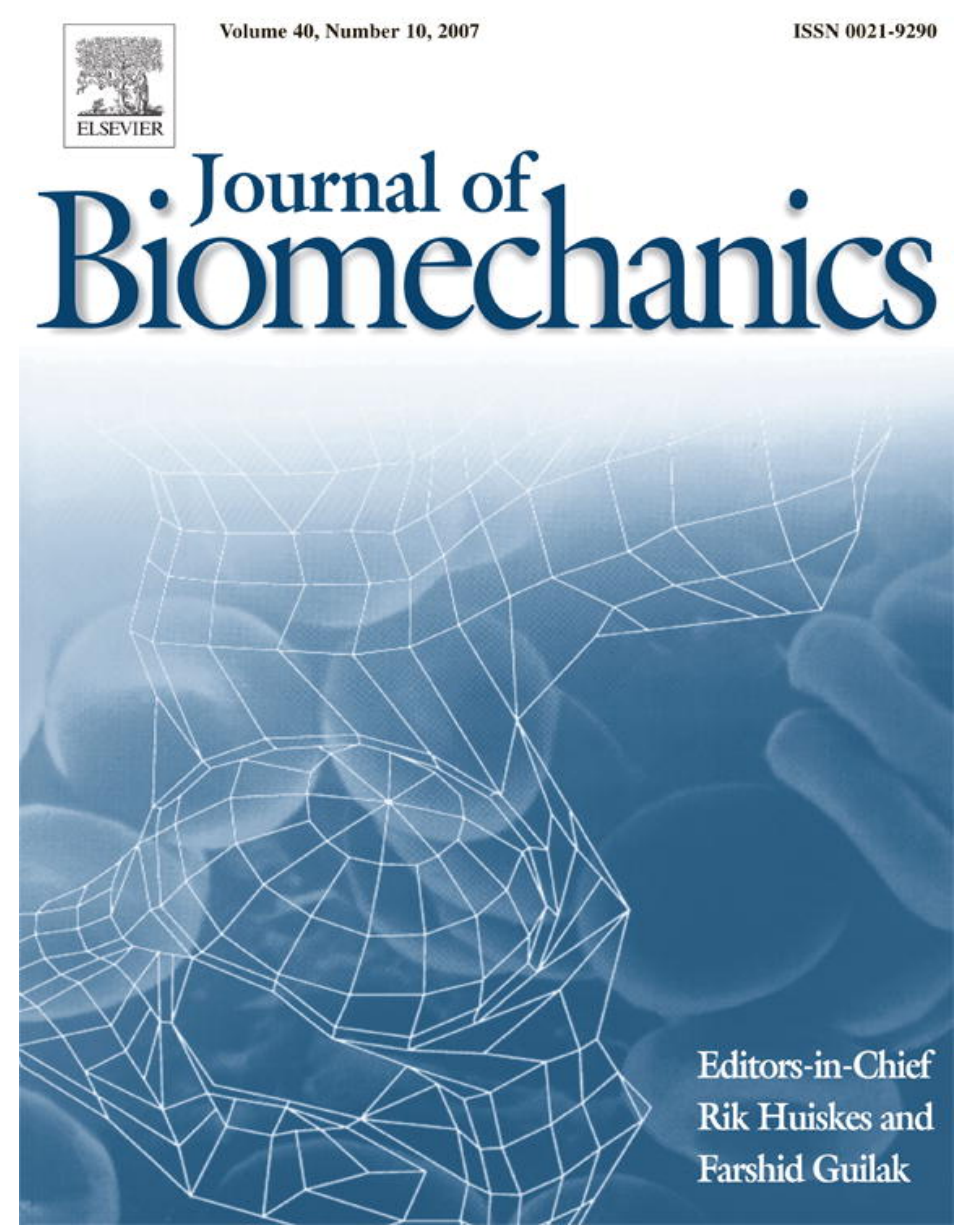

This article was originally published in a journal published by Elsevier, and the attached copy is provided by Elsevier for the author's benefit and for the benefit of the author's institution, for non-commercial research and educational use including without limitation use in instruction at your institution, sending it to specific colleagues that you know, and providing a copy to your institution's administrator.

All other uses, reproduction and distribution, including without limitation commercial reprints, selling or licensing copies or access,

or posting on open internet sites, your personal or institution's website or repository, are prohibited. For exceptions, permission may be sought for such use through Elsevier's permissions site at: 


\title{
Intrinsic mechanical properties of trabecular calcaneus determined by finite-element models using 3D synchrotron microtomography
}

\author{
H. Follet ${ }^{\mathrm{a}, *}$, F. Peyrin ${ }^{\mathrm{b}, \mathrm{c}}$, E. Vidal-Salle ${ }^{\mathrm{a}}$, A. Bonnassie ${ }^{\mathrm{b}}$, C. Rumelhart ${ }^{\mathrm{a}}$, P.J. Meunier ${ }^{\mathrm{d}}$ \\ ${ }^{a}$ Laboratoire de Mécanique des Contacts et des Solides (LaMCoS) UMR CNRS 5514, INSA, Bât Coulomb, Lyon, France \\ ${ }^{\mathrm{b}}$ CREATIS, UMR CNRS 5515, Bât. Blaise Pascal, INSA, Lyon, France \\ ${ }^{\mathrm{c}}$ ESRF, BP 220, 38043 Grenoble Cedex, France \\ ${ }^{\mathrm{d}}$ Laboratoire d'Histodynamique Osseuse, INSERM U403, Lyon, France
}

Accepted 24 October 2006

\begin{abstract}
To determine intrinsic mechanical properties (elastic and failure) of trabecular calcaneus bone, chosen as a good predictor of hip fracture, we looked for the influence of image's size on a numerical simulation. One cubic sample of cancellous bone $\left(9 \times 9 \times 9 \mathrm{~mm}^{3}\right)$ was removed from the body of the calcaneus ( 6 females, 6 males, $79 \pm 9 \mathrm{yr})$. These samples were tested under compressive loading. Before compressive testing, these samples were imaged at $10.13 \mu \mathrm{m}$ resolution using a 3D microcomputed tomography $(\mu \mathrm{CT})(\mathrm{ESRF}, \mathrm{France})$. The $\mu \mathrm{CT}$ images were converted to finite-element models. Depending on the bone density values (BV/TV), we compared two different finite element models: a linear hexahedral and a linear beam finite element models. Apparent experimental Young's modulus $\left(E_{\mathrm{app}}^{\text {exp }}\right)$ and maximum apparent experimental compressive stress $\left(\sigma_{\max }^{\exp }\right)$ were significantly correlated with bone density obtained by Archimedes's test $\left(E_{\mathrm{app}}^{\exp }=236 \pm 231 \mathrm{MPa}[19-742 \mathrm{MPa}], \sigma_{\max }^{\exp }=2.61 \pm 1.97 \mathrm{MPa}[0.28-5.81 \mathrm{MPa}], r>0.80, p<0.001\right)$. Under threshold at $40 \mu \mathrm{m}$, the size of the numerical samples $\left(5.18^{3}\right.$ and $\left.6.68^{3} \mathrm{~mm}^{3}\right)$ seems to be an important parameter on the accuracy of the results. The numerical trabecular Young's modulus was widely higher $\left(E_{\text {trabecular }}^{\text {num }}=34,182 \pm 22,830 \mathrm{MPa}\right.$ [9700-87,211 MPa]) for the larger numerical samples and high BV/TV than those found classically by other techniques $(4700-15,000 \mathrm{MPa})$. For rod-like bone samples $(\mathrm{BV} / \mathrm{TV}<12 \%, n=7)$, Young's modulus, using linear beam element ( $\left.E_{\text {trabecular }}^{\text {num-sklon }} 10,305 \pm 5500 \mathrm{MPa}\right)$, were closer to the Young's modulus found by other techniques. Those results show the limitation of hexahedral finite elements at $40 \mu \mathrm{m}$, mostly used, for thin trabecular structures.
\end{abstract}

(C) 2006 Elsevier Ltd. All rights reserved.

Keywords: Microcomputed tomography $(\mu \mathrm{CT})$; Finite-element models; Biomechanical strength; Trabecular bone; Calcaneus

\section{Introduction}

To predict if a bone will break is a tremendous challenge. In the near future, the clinical examinations associated to the numerical simulations from clinical scanners will certainly be used to predict the bone fracture risk. But, before that, clinical numerical simulations need to be adjusted depending on the bone quality (plate/rod-like trabecular bone) and accurate comparing to the bone size.

\footnotetext{
*Corresponding author. Department of Anatomy and Cell Biology, Indiana University School of Medicine, MS-5035, 635, Barnhill Drive, Indianapolis, IN 46202, USA. Tel.: + 131727423 15; fax: +13172782040 .

E-mail address: helene.follet@sante.univ-lyon1.fr (H. Follet).
}

In clinical routine, computed tomography (CT) allows nondestructive imaging of two-dimensional (2D) transverse slices of human anatomy but their resolution $(300 \mu \mathrm{m})$ is insufficient for imaging thin structures such as trabecular bone architecture $(\sim 100 \mu \mathrm{m})$. In the past, several investigators have tried to establish relationships that could predict bone mechanical properties from measurement of bone density and architectural features (Cowin, 1985; Goulet et al., 1994; Hollister et al., 1994; Turner et al., 1990). In these studies, the mechanical properties of sample trabecular bone cubes were determined from compression tests. Van Rietbergen et al. used models that describe the trabecular structure, and used three-dimensional (3D) serial reconstruction techniques to construct a large-scale finite-element (FE) model, by directly converting voxels to 
elements (Van Rietbergen et al., 1995, 1996, 1997a,b, 1998). Yeh et al. investigated a 3D FE parameter study (beam type FE) that simulated variations in trabecular thickness (either $25 \%, 40 \%$, or $55 \%$ ) applied to an irregularly spaced lattice of different sized rods (Yeh and Keaveny, 1999). Keaveny et al. suggested the use of highresolution microstructural FE models (Keaveny et al., 1993, 2001, Niebur et al., 2001). Niebur et al. also used high-resolution $(40 \mu \mathrm{m}) \mathrm{FE}$ models for trabecular bone failure to increase the accuracy of current techniques to measure damage in trabecular bone (Niebur et al., 2001). Using quantitative computed tomography (QCT), Kopperdahl et al. obtained density-mechanical property regressions for trabecular bone and used them in biomechanical modeling of the human spine (Kopperdahl et al., 2002). Crawford et al. investigated the numerical convergence characteristics of specimen-specific "voxel-based" FE models of 14 excised human cadaver lumbar vertebral bodies that were generated automatically from clinical-type CT scans (Crawford et al., 2003a).

The aim of this study was (1) to determine intrinsic hard tissue mechanical properties for trabecular calcaneus bone, (2) to show if the $5 \mathrm{~mm}$-side criterion is an enough criterion to estimate the mechanical properties of trabecular bone, (3) to show the limitation of hexahedral FE at $40 \mu \mathrm{m}$, when used for thin trabecular structures, via two different microcomputed tomography $(\mu \mathrm{CT})$-based $\mathrm{F}$ E models (hexahedral and beam) and compressive testing, (4) to show that the type of element (plate/rod-like bone) has to be taken account in the future simulation. In our knowledge, unlike previously published work (Van Rietbergen et al., 1995)., the comparison between different FE models and size associated to an experimental design on calcaneus have not been done.

\section{Material and methods}

\subsection{Material and protocol}

Calcanei were excised at autopsy from 12 subjects

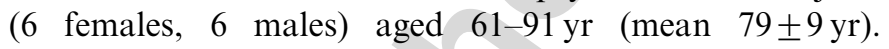
Conventional radiographs (X-rays) were first taken to exclude bones with disease and to identify the superior network of the trabecular bone (Figs. 1(a) and (b)) (Gefen and Seliktar, 2004; Kapandji, 1994; Putz and Pabst, 1994). One cubic sample $(9 \mathrm{~mm} / \mathrm{side})$ oriented along the superior trabecular network was cut out from the calcaneus using a low speed diamond water saw (Buehler, Isomet $^{\circledR}$, Fig. 1(c)). First, the frozen samples were imaged using $3 \mathrm{D} \mu \mathrm{CT}$ imaging to obtain 3D and 2D morphometric parameters (Figs. 1(c) and 2(a)). Then, they were used for compressive tests. Between machining and mechanical testing, samples were kept frozen and, before mechanical testing, they were placed in a $50 \%$ saline-ethanol solution for $3 \mathrm{~d}$ at $4{ }^{\circ} \mathrm{C}$ for defrosting and at ambient temperature for 2-4h (Ashman et al., 1984). After compressive testing, the cubic samples were defatted to measure apparent and tissue densities.

\section{2. $3 D$ synchrotron radiation $\mu C T$ imaging}

3D high-resolution tomographic images were acquired at the ESRF (Grenoble, France) which provides 3D images at very high spatial resolution with a high signal to noise ratio within a limited acquisition time (Salome et al., 1999). Image acquisition was performed using a monochromatic $\mathrm{x}$-ray beam fixed to $25 \mathrm{keV}$. For each sample, 900 radiographic images $(1024 \times 1024)$, under different angles of view, were recorded. The spatial resolution in the recorded images was set to $10.13 \mu \mathrm{m}$, which has been previously shown to provide an accurate rendering of bone architecture while maintaining a significant field of view $\left(10 \times 10 \times 10 \mathrm{~mm}^{3}\right)($ Peyrin et al., 1998, 2000). The 3D images were then obtained by applying an exact tomographic reconstruction algorithm, based on filtered backprojection. The voxel size in the reconstructed images was $10 \times 10 \times 10 \mu \mathrm{m}^{3}$. A centered $3 \mathrm{D}$ region of interest (ROI) made of $(660)^{3}$ voxels $\left(6.6^{3} \mathrm{~mm}^{3}\right)$ was selected in each sample for performing the $3 \mathrm{D}$ architectural analysis.

\subsection{D analysis}

Due to the high contrast and low noise level, the 3D images were easily segmented using simple threshold. After segmentation, 3D architectural parameters, similar to those used in histomorphometry, were computed from the 3D binary images including a 3D version of the mean intercept length (MIL) method (Compston et al., 1993; Simmons and Hipp, 1997), partial bone volume (BV/TV in \%), direct trabecular thickness ( $\mathrm{TbTh}^{*}$ in $\mathrm{mm}$ ), trabecular number $\left(\mathrm{TbN}\right.$ in $\left.\mathrm{mm}^{-1}\right)$, and trabecular separation ( $\mathrm{TbSp}$ in $\left.\mathrm{mm}\right)$. For computing skeletons, we used a method based on thinning where the object boundary is sequentially removed under some conditions, which guarantees the preservation of the topology (Lee et al., 1994; Thovert et al., 1993). The method was applied to rod-like bones and provided a line skeleton. In order to reduce artifacts, parasitic branches over a certain length were suppressed. Examples of typical rod-like or plate-like bones obtained from 3D $\mu \mathrm{CT}$ and their 3D skeletons are presented in Figs. 2(a) and (b).

\subsection{Compressive tests}

As previously published (Cendre et al., 1999; Follet et al., 2005) unconstrained compressive testing was performed on calcaneus trabecular specimens (cube of $9 \times 9 \times 9 \mathrm{~mm}^{3}$, Schenck RSA 250, Fig. 3). The compressive load was measured by a $2000 \mathrm{~N}$ load cell $\left(\mathrm{TME}^{\circledR}, \mathrm{F} 501 \mathrm{TC}\right.$, accuracy $0.1 \%$ ) and a specific displacement was measured directly on the sample (transducer developed at LaMCoS, Cendre et al., 1999; Mitton et al., 1998). Samples were placed in a saline solution at $37^{\circ} \mathrm{C}$. 

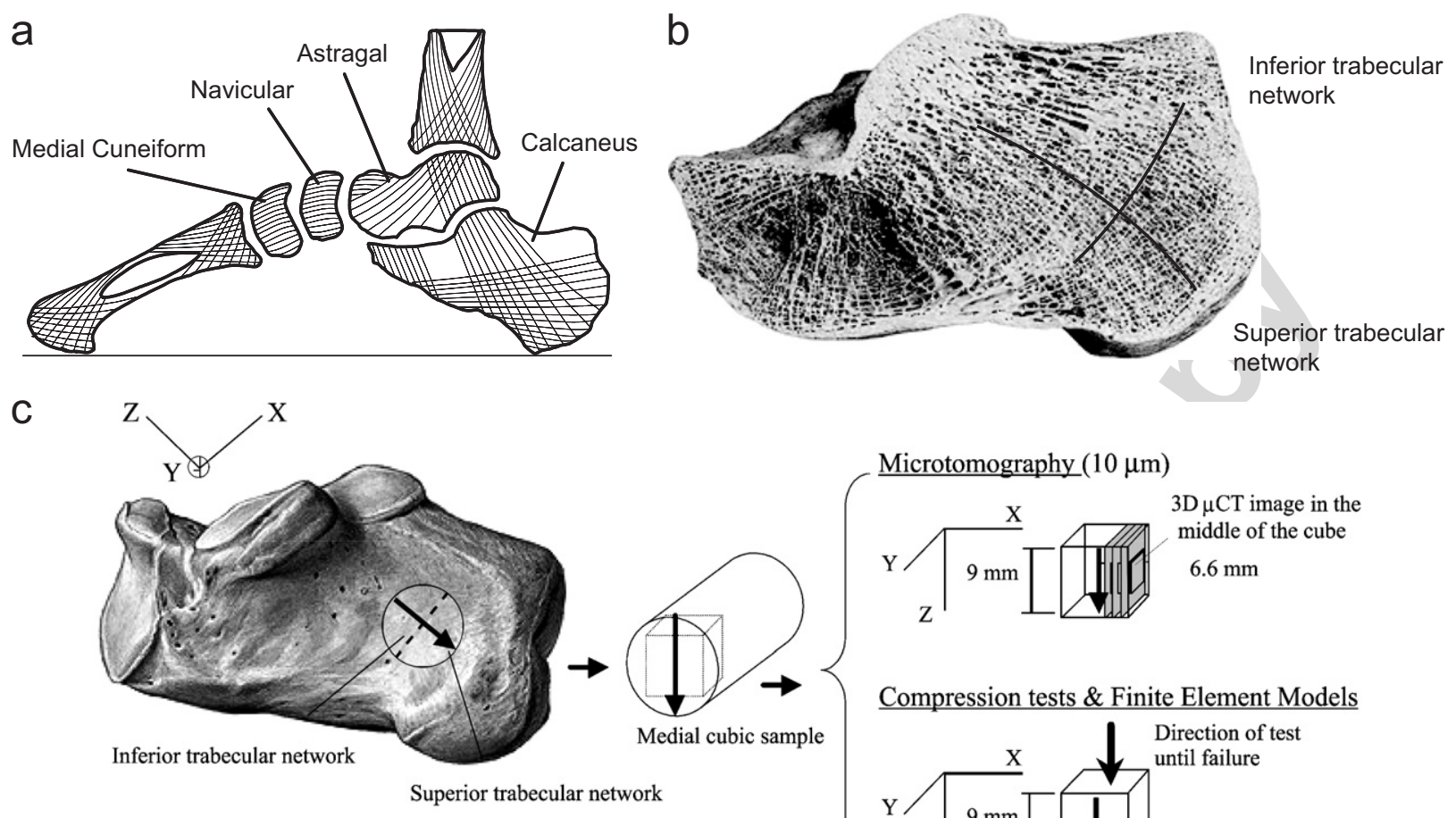

Medial view (right calcaneus)

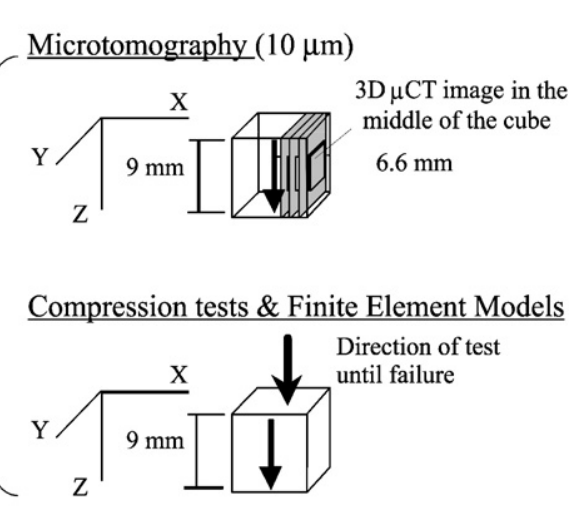

Fig. 1. Scheme of the trabecular structure in intern arch of foot by Kapandji (Kapandji, 1994). (a) Longitudinal cut and main trabecular network by Putz (Putz and Pabst, 1994). (b) Testing protocol showing the location of the cubic sample and the orientation for 3D imaging and (c) mechanical tests.
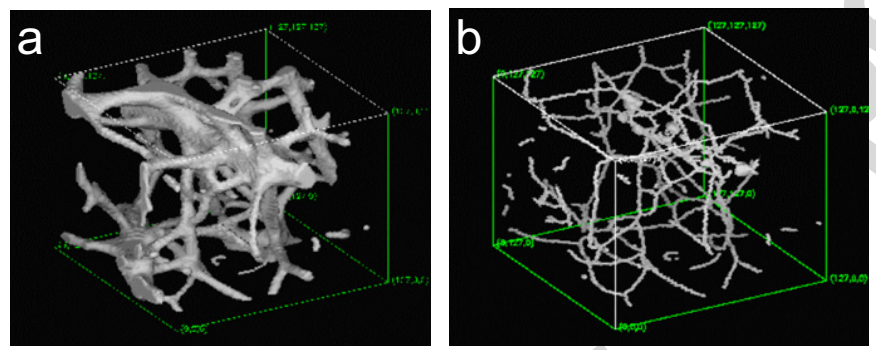

Fig. 2. 3D computed image from a rod-like bone. (a) Rod-like bone reconstruction and (b) skeleton obtained on the same sample by homotopic thinning technique.

All tests were performed at a displacement speed of $0.5 \mathrm{~mm} / \mathrm{min}$ and preceded by 10 cycles of preloading. Preloading and nondestructive compression were limited to $0.5 \%$ of strain and performed successively in three orthogonal directions: the anteroposterior direction $(X$-axis), the mediolateral direction ( $Y$-axis) and the superior direction ( $Z$-axis), determinated by radiographs. The experimental apparent Young's moduli $\left(E_{\mathrm{app}}^{\exp (x)}, E_{\mathrm{app}}^{\exp (y)}, E_{\mathrm{app}}^{\exp (z)}\right)$ were calculated considering the apparent sections of the cubic sample and the linear part of the force-displacement curves in the elastic region. After that, a destructive test was carried out in the $Z$ direction. The apparent Young's modulus $E_{\text {app }}^{\exp }$ and the apparent maximum compressive stress $\sigma_{\max }^{\exp }$ were evaluated from the force-displacement curve, considering the apparent section of the sample. According to the ASTM, the apparent Young's modulus was determined from the linear portion of the stress-strain curve. Two data points were chosen on the linear portion of the curve by inspection and a linear regression was performed on the data between the chosen points. If the $r^{2}$ values were less than 0.99 for the resulting regression, two other points were chosen and the process was repeated (ASTM, 1992).

\subsection{Density}

After mechanical testing, cubic samples were defatted by chemical action ( $48 \mathrm{~h}$ toluene) followed by both chemical and mechanical actions (ultrasonic stirring in a $2 \%$ chlorine bath). Dehydration was obtained by drying for $24 \mathrm{~h}$ in air at room temperature. Particular care was taken to prevent air being trapped in marrow cavities. A centrifugation was used to remove air from the specimens. Apparent density $\rho_{\text {app }}$, tissue density $\rho_{\text {tissue }}$ and bone volume estimated by Archimedes principle $\left(\rho_{\text {app }} / \rho_{\text {tissue }}\right)$ were defined (see Appendix).

\subsection{FE models}

FE models were built using $\mu \mathrm{CT}$ volume of cubic sample. Due to the high resolution on the $\mu \mathrm{CT}$ volume of cubic 


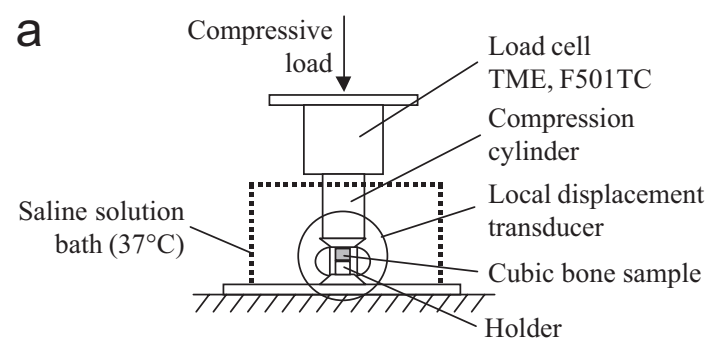

b

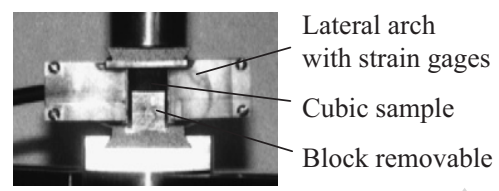

Fig. 3. Description of the equipment used for compressive tests. (a) Plan and (b) local displacement transducer.
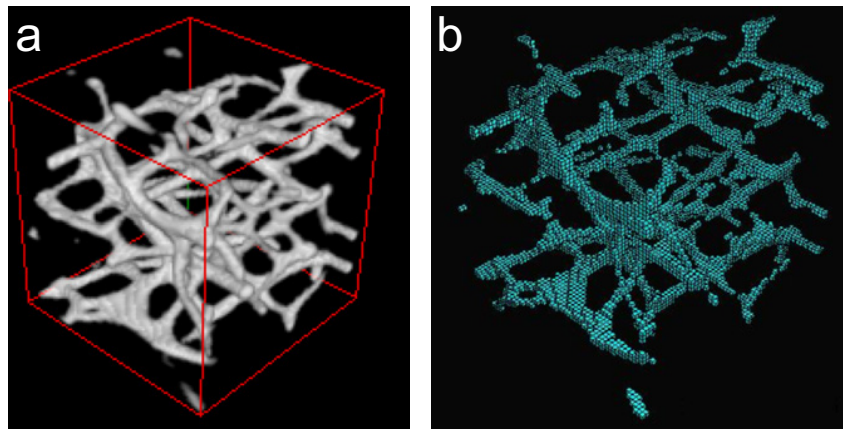

Fig. 4. Example of trabecular bone of calcaneus (a) by microcomputed tomography at $40 \mu \mathrm{m}$ and (b) by finite element model: 8 nodes-hexahedral element.

samples $(10.13 \mu \mathrm{m})$, all these volumes were under threshold at $40 \mu \mathrm{m}$ to build FE models. This step was required because using high resolution $(10.13 \mu \mathrm{m})$ increases the number of equations to be solved by 64 times. FE models of trabecular cubic samples of calcaneus were created by converting each bone voxel to a FE (Fig. 4). Most of these simulations were done at CINES (Montpellier, France), with one SGI ORIGIN 3800, with a scientific FE code Abaqus $\AA /$ Standard 6.2.

Hexahedral models ( 8 nodes) with two different sizes were built and simulated: $1 \mathrm{st}-128$ voxels per side $(5.18 \mathrm{~mm}$ side, $\left.140 \mathrm{~mm}^{3}, n=12\right), 2 \mathrm{nd}-165$ voxels per side $(6.68 \mathrm{~mm}$ side, $299 \mathrm{~mm}^{3}, n=12$ ). The smallest trabecular model that we built was 65,000 elements and the largest model the computer's capacity was able to build was 746,000 elements. After those simulations, thin samples (BV/ $\mathrm{TV}<12 \%$ ) have been both built with hexahedral model $(n=12)$ and beam elements ( 2 nodes, $n=7)$.

A C ++ program, developed at the LaMcoS, converted each voxel on the $\mu \mathrm{CT}$ volume into an 8-node-hexahedral element (Fig. 4). For the beam model, skeleton image were used to build 3D beam element model, and one voxel represented the trabecular thickness (Fig. 2). A beam element is defined as a beam, with a circular section and two nodes, one at each end. The beam model considers each voxel of bone tissue as a node. The centers of two adjacent voxels constitute the two ends of a 2-node-beam

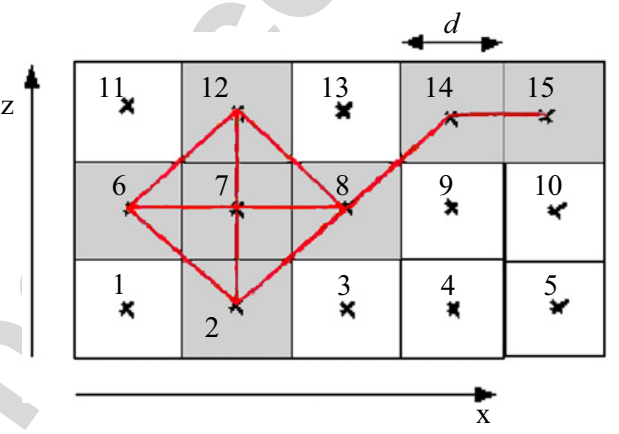

Fig. 5. 2D Scheme of the finite beam element built. Gray pixels represent bone. A beam links each gray pixel (voxel in 3D). For example, pixel number 2 can be linked to pixel number 7 (beam length $=d$ ), to pixel 8 (beam length $=d \sqrt{ } 2$ ), and to a pixel in a upper level (beam length $=d \sqrt{ } 3$ ). A final treating eliminated the double beams (between pixels $2-8$ and $8-2$ ). a

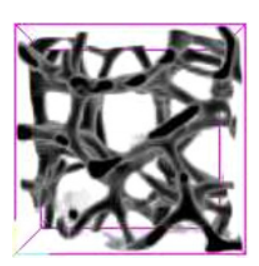

b

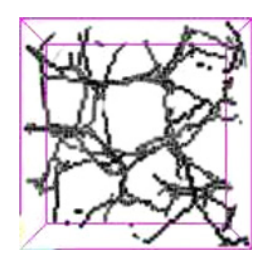

C

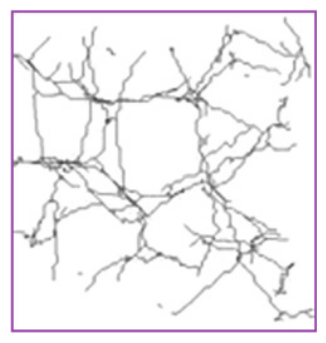

Fig. 6. Example of skeleton. (a) Initial tomography volume, (b) skeleton based on wall reducing (homotopic thinning technique) and (c) corresponding finite element, using beam element.

element (Fig. 5). The adjacency of two nodes was determined comparing the distance of each voxel center to a distance equal to voxel size $d, \sqrt{ } 2 d$ or $\sqrt{ } 3 d$. A final treating allows eliminating the double beams (Fig. 5). A circular beam section is chosen in order to avoid deviations in bending behavior. A mean section $\left(\pi R^{2}, R\right.$ section radius) was calculated by using $\mathrm{TbTh}$ *obtained by $\mu \mathrm{CT}$ at $10 \mu \mathrm{m}$ (Fig. 6) for each sample. Based on the values of the $\mathrm{TbTh}^{*}$, the section radius $\mathrm{R}$ is chosen to obtain a beam section with a radius $R \sim \mathrm{TbTh}^{*}$, and $R$ is adjusted to 
obtain a beam FE density equal to the hexahedral FE density. The FE density corresponds to the total volume of the total number of elements compared to the entire cube. The FE density is then similar to the ratio bone volume/ tissue volume. For both models, we used an isotropic and linear elastic behavior law, with an arbitrary elastic numerical Young's modulus $\left(E_{\text {trabecular }}^{\text {num initial }}=8000 \mathrm{MPa}\right)$ and a Poisson's ratio $(v=0.3)$ at the first step of the calculation. The tissue properties were estimated by scaling the apparent modulus computed by using $E_{\text {trabecular }}^{\text {num initial }}$ to match the experimentally determined value as follows:

$E_{\text {trabecular }}^{\text {num }}=E_{\text {trabecular }}^{\text {num initial }} \frac{E_{\text {app }}^{\exp } \varepsilon}{\sigma_{\text {max }}^{\text {nupp }}}$

where $\varepsilon$ is the axial apparent strain $(0.5 \%)$ implemented in the simulation.

The choice of $E_{\text {trabecular }}^{\text {num initial }}$ is arbitrary but does not hold any significance because the simulations are linear elastic and the values can be scaled to match the experimental results.

Boundary conditions were chosen to simulate the compressive testing conditions. The model was loaded in the superior trabecular network direction by a distributed imposed translation corresponding to the force applied on the superior side; nodes on the inferior side were constrained in the superior trabecular network direction, and able to slip in the two other directions. The magnitude of the total applied force was depending on deformation, limited to $0.5 \%$ of deformation in the superior network direction ( $Z$-axis).

\subsection{Statistics}

Descriptive statistics were summarized by mean value, standard deviation, median and range. Mechanical para- meter or their logarithmic transformations ( $\mathrm{Ln} E$ ) were normally distributed. According to their distribution, differences between 3D parameters were assessed by a paired $t$-test for parametric test, and by Wilcoxon pair $T$ test for nonparametric test. The relationships between normally distributed parameters were evaluated by Pearson correlation coefficients $r$ for parametric variables, and by Spearman correlation coefficient $r^{\prime}$ for nonparametric variables. The degree of significance was assessed according to Bonferroni's procedure $(p \leqslant 0.01$ indicates a significant correlation, Unistat ${ }^{\circledR} 5.5$, SPSS $\left.^{\circledR} 11.5\right)$.

\section{Results}

\subsection{Density and compressive properties}

Density measurements and mechanical elastic properties obtained after compressive testing $(Z)$ are shown in Table 1. The Young's modulus obtained from the destructive test $\left(E_{\text {app }}^{\exp }\right)$ was significantly correlated with the Young's modulus obtained during the elastic test $E_{\mathrm{app}}^{\exp (z)}$ $(r=0.996, p<0.0001, n=12)$ and with the maximum compressive stress $\sigma_{\max , \text { app }}^{\exp }(r=0.96, p<0.0001, n=12)$. All the mechanical parameters were significantly correlated with the apparent density: $E_{\mathrm{app}}^{\exp }(r=0.87, p<0.0001$, $n=12)$, and $\sigma_{\max , \text { app }}^{\exp }(r=0.95, p<0.0001, n=11)$, with the tissue density: $E_{\text {app }}^{\exp }(r=0.60, p<0.001), \sigma_{\max , \text { app }}^{\exp }$ $(r=0.68, p<0.001)$ and with the bone fraction volume obtained by Archimedes test $\rho_{\text {app }} / \rho_{\text {tissue }}: E_{\text {app }}^{\exp }(r=0.84$, $p<0.001), \sigma_{\max \text { app }}^{\exp }(r=0.92, p<0.001)$.

\subsection{FE analysis}

\subsubsection{Model size influence}

The aim was to compare results of two FE models based on cubes of $5.18 \mathrm{~mm}$ (128 voxels side, $140 \mathrm{~mm}^{3}, n=12$ )

Table 1

Density and mechanical characteristics of human calcanei, $n=12,79 \pm 9 \mathrm{yr}(61-91 \mathrm{yr})$

\begin{tabular}{|c|c|c|c|c|c|c|}
\hline \multirow[t]{2}{*}{ Parameters } & \multicolumn{6}{|c|}{ Medial cubic sample } \\
\hline & $n$ & Mean & $\mathrm{SD}$ & Median & Range & $p$ \\
\hline \multicolumn{7}{|l|}{ Densities } \\
\hline$\rho_{\text {app }}\left(\mathrm{g} / \mathrm{cm}^{3}\right)$ & 12 & 0.19 & 0.09 & 0.18 & $0.07-0.33$ & \\
\hline$\rho_{\text {tissue }}\left(\mathrm{g} / \mathrm{cm}^{3}\right)$ & 12 & 2.02 & 0.10 & 2.06 & $1.87-2.15$ & $<0.05^{\mathrm{c}}$ \\
\hline$\rho_{\text {app }} / \rho_{\text {tissue }}(\%)$ & 12 & 9.19 & 4.10 & 8.86 & $3.36-15.25$ & \\
\hline $\mathrm{BV} / \mathrm{TV}_{\mu \mathrm{CT}}(\%)$ & 12 & 10.17 & 4.05 & 10.54 & $3.68-17.14$ & \\
\hline \multicolumn{7}{|l|}{ Biomechanics } \\
\hline$E_{\text {app }}^{\exp }(\mathrm{MPa})$ & 12 & 236 & 231 & 189 & $19-742$ & $<0.0001^{\mathrm{a}, \mathrm{b}, \mathrm{c}}$ \\
\hline$\sigma_{\max , \text { app }}^{\exp }(\mathrm{MPa})$ & 11 & 2.61 & 1.97 & 2.30 & $0.28-5.81$ & $<0.0001^{\mathrm{c}}$ \\
\hline
\end{tabular}

SD, standard deviation; $\rho_{\text {app }}$, apparent density; $\rho_{\text {tissues }}$, tissue density; $\rho_{\text {app }} / \rho_{\text {tissue }}$, bone volume fraction obtained by Archimedes principle. $E_{\text {app }}$, experimental apparent Young's modulus along the main axis; $\sigma_{\max }^{\exp }$ app, maximal experimental apparent stress.

\footnotetext{
${ }^{\text {a With }} E_{\text {app }}^{\exp }$

${ }^{\mathrm{b}}$ With $\sigma_{\max , \text { app }}^{\mathrm{exp}}$

${ }^{\mathrm{c}}$ With $\rho_{\text {app. }}$
} 
Table 2

Numerical Young's modulus $E_{\text {trabecular }}^{\text {num-hedral }}$ obtained by hexahedral finite element on two cubic sample's size

Numerical Young's modulus $E_{\text {trabecular }}^{\text {num-hexahedral }}(\mathrm{MPa})$

\begin{tabular}{llllr}
\hline Volume $\left(\mathrm{mm}^{3}\right)$ & $n$ & Mean & SD & Median \\
\hline $5.18^{3}\left(140 \mathrm{~mm}^{3}\right)$ & 12 & 37,340 & 29,595 & 27,453 \\
$6.68^{3}\left(299 \mathrm{~mm}^{3}\right)$ & 12 & 34,182 & 22,830 & $9379-97,499$ \\
\hline
\end{tabular}

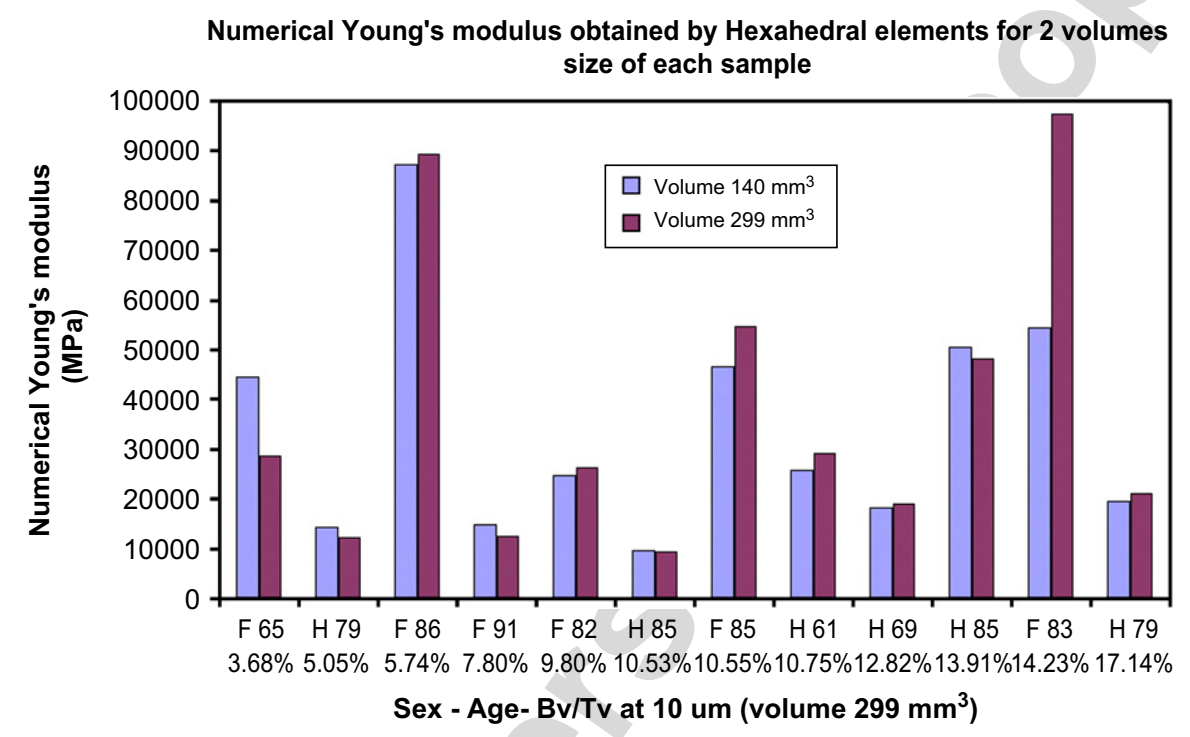

Fig. 7. Numerical Young's modulus obtained by hexahedral elements for two volumes sizes $\left(140-299 \mathrm{~mm}^{3}\right)$.

and $6.68 \mathrm{~mm}$ (165 voxels side, $\left.299 \mathrm{~mm}^{3}, n=12\right) . \mathrm{A}$ comparison test (pair $t$-test) has shown a significant difference $(p<0.05)$ on numerical Young's modulus between these two models. However, a significant correlation was found (Pearson coefficient $r^{2}=0.82, p<0.001$, $n=12$ ) between numerical trabecular Young's modulus obtained by finite hexahedral element on a $299 \mathrm{~mm}^{3}$ volume and the one $140 \mathrm{~mm}^{3}$ volume (after logarithmic transformation for Young's modulus) (Table 2, Fig. 7).

\subsubsection{Element type influence}

Results obtained with hexahedral and beam elements are shown in Fig. 8. There was a significant difference ( $t$-test, $p<0.05)$ between the circular beam section radius $R$ and the direct trabecular thickness TbTh*. But, a high significant correlation $(r=0.979, p<0.05)$ was found between these two parameters. There is a significant difference (paired $t$-test, $p<0.05$ ) between bone volume obtained by microtomography at $10.13 \mu \mathrm{m}$ on cubic sample and bone volume fraction obtained using hexahedral models and bone volume obtained by Archimedes test $\rho_{\text {app }} / \rho_{\text {tissue }}$ (mean: $\mathrm{BV} / \mathrm{TV}_{\mu \mathrm{CT}}$ : $7.62 \pm 2.85 \%, \mathrm{BV} / \mathrm{TV}_{\text {hexahedral }}: 7.17 \pm 2.90 \%, \rho_{\text {app }} / \rho_{\text {tissue }}$ :
$6.47 \pm 2.50 \%$ ). However highly significant correlations were found between the bone density and the 'FE' density ( $r^{2}=0.99, p<0.001$ and $r^{2}=0.93, p<0.001$ respectively). A significant correlation was found between the trabecular thickness $\mathrm{TbTh}^{*}$ and the apparent Young's modulus $E_{\mathrm{app}}^{\exp }$ $\left(r^{2}=0.58, p<0.05\right)$. Numerical Young's modulus $E_{\text {trabecular }}^{\text {num }}$ has a significant correlation with bone volume $(\mathrm{BV} / \mathrm{TV})$, in particular with the one $\left(\mathrm{BV} / \mathrm{TV}_{\text {hexahedral }}\right)$ obtained on hexahedral models $\left(r^{2}=0.61, p<0.05\right)$ (Table 3$)$. Numerical Young's modulus ( $\left.E_{\text {trabecular }}^{\text {num-skeleto }}\right)$ obtained with skeleton models was found to be 3-fold smaller than the one calculated with hexahedral models (mean: $E_{\text {trabecular }}^{\text {num-skelen: }}$ $\left.10,305 \pm 5500 \mathrm{MPa}, \quad E_{\text {trabecular }}^{\text {num-hexal }}: \quad 31,580 \pm 2700 \mathrm{MPa}\right)$, (Table 3 and Fig. 8). For one of the samples, there is a 8fold difference between Young's modulus calculated by beam and hexahedral models. With or without this sample, there is a significant difference ( $p=0.018$, Wilcoxon $T$-test) in the calculation of Young's modulus and a high significant correlation (Spearman coefficient) was found between these two parameters $\left(r^{\prime}=0.89, p<0.01, n=7\right)$. Comparing results obtained for different models, $E_{\text {app }}^{\exp }$ is not correlated to $E_{\text {trabecular }}^{\text {num-hexahed }}\left(r^{2}=-0.1, p>0.84, n=5\right)$, but is related, without significance, to $E_{\text {trabecular }}^{\text {num-skelon }}$ 


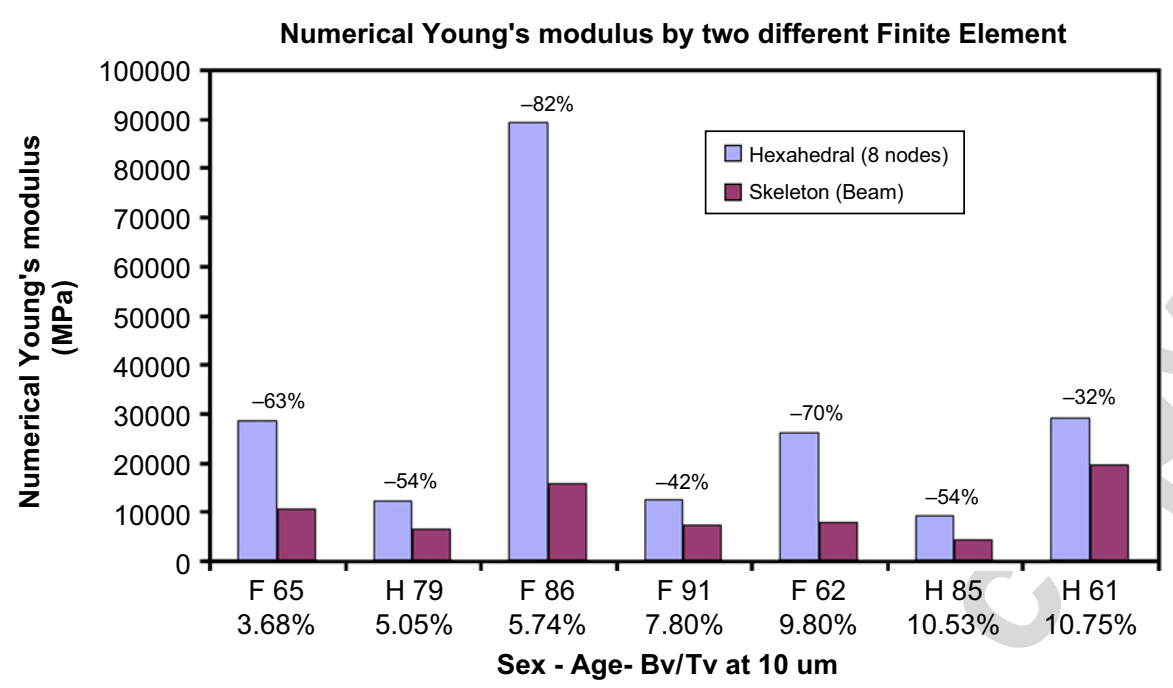

Fig. 8. Comparison between numerical Young's modulus obtained by hexahedral element and by beam element (elastic law behavior). Note that the percentage difference between hexahedral and beam models are shown next to each bar.

Table 3

Density and mechanical characteristics of human calcanei after finite element modeling (mean age $78 \pm 11 \mathrm{yr}, n=7$, range (61-91 yr))

\begin{tabular}{|c|c|c|c|c|c|}
\hline Parameters & $n$ & Mean & SD & Median & Range \\
\hline \multicolumn{6}{|c|}{ Densities and $B V / T V(\%)$} \\
\hline$\rho_{\text {app }} / \rho_{\text {tissue }}{ }^{\mathrm{a}}$ & 7 & 6.47 & 2.50 & 6.41 & $3.36-9.11$ \\
\hline $\mathrm{BV} / \mathrm{TV}_{\mu \mathrm{CT}}{ }^{\mathrm{b}}$ & 7 & 7.62 & 2.85 & 7.80 & $3.68-10.75$ \\
\hline $\mathrm{BV} / \mathrm{TV}_{\text {hexahedral }}{ }^{\mathrm{c}}$ & 7 & 7.17 & 2.90 & 7.54 & $3.23-10.72$ \\
\hline $\mathrm{BV} / \mathrm{TV}_{\text {skeleton }}{ }^{\mathrm{d}}$ & 7 & 7.17 & 2.90 & 7.54 & $3.23-10.72$ \\
\hline \multicolumn{6}{|c|}{ Experimental Mechanical Properties (MPa) } \\
\hline$E_{\mathrm{app}}^{\exp }$ & 7 & 83 & 58 & 86 & 19-189 \\
\hline$\sigma_{\max , \text { app }}^{\exp }$ & 7 & 1.12 & 0.89 & 0.85 & $0.29-2.30$ \\
\hline $\operatorname{TbTh}^{*}(\mu \mathrm{m})^{\mathrm{g}}$ & 7 & 122.95 & 23.16 & 118.44 & $85.39-153.41$ \\
\hline \multicolumn{6}{|c|}{ Numerical Young's modulus ( $\mathrm{Mpa}$ ) } \\
\hline$\sigma_{\text {max, app }}^{\text {num-skeleton }}{ }^{\mathrm{h}}$ & 7 & 243 & 210 & 132 & $80-330$ \\
\hline$E_{\text {trabecular }^{\text {num-keleton }}}^{\mathrm{i}}$ & 7 & 10,305 & 5500 & 7780 & $4360-19,750$ \\
\hline$E_{\text {trabecular }}^{\text {numedral }}{ }^{\mathrm{j}}$ & 7 & 31,580 & 27,100 & 24,770 & $9700-87,200$ \\
\hline
\end{tabular}

${ }^{\mathrm{a}} \rho_{\text {app }} / \rho_{\text {tissue: }}$ bone volume obtained by Archimedes's test.

${ }^{\mathrm{b}} \mathrm{BV} / \mathrm{TV}_{\mu \mathrm{CT}}$ : bone volume obtained by $\mu \mathrm{CT}$ at $10 \mu \mathrm{m}$ on medial sample.

${ }^{\mathrm{c}} \mathrm{BV} / \mathrm{TV}_{\text {hexahedral: }}$ bone volume obtained on hexahedral models.

${ }^{\mathrm{d}} \mathrm{BV} / \mathrm{TV}_{\text {skeleton }}$ : bone volume obtained on skeleton models, and adjusted to the $\mathrm{BV} / \mathrm{TV}_{\text {hexahedral }}$

${ }^{\mathrm{e}} E_{\mathrm{app}}^{\mathrm{exp}}$ : apparent experimental Young's modulus.

${ }^{\mathrm{f}} \sigma_{\max , \text { app }}^{\mathrm{exp}}$ : maximum compressive stress.

${ }^{\mathrm{g}}$ Direct trabecular thickness obtained by $\mu \mathrm{CT}$ at $10 \mu \mathrm{m}$.

${ }^{\mathrm{h}} \sigma_{\max , \text { app }}^{\text {num-kelen }}$ : maximum compressive stress on skeleton models.

${ }^{\mathrm{i}}$ Numerical Young's modulus on skeleton models.

${ }^{\mathrm{j}}$ Numerical Young's modulus on hexahedral models.

$\left(r^{2}=0.57, p<0.2, n=7\right)$ and a significance was found between the two numerical Young's moduli $\left(r^{2}=0.89\right.$, $p<0.03, n=7)$.

\section{Discussion}

Intrinsic mechanical properties of trabecular bone were determined using experimentally measured mechanical properties and FE models built from $\mu \mathrm{CT}$. We have shown that the size of the imaging sample was an important parameter on determining numerical Young's modulus values. Small FE dimensions could induce mistakes in interpretation of results. From a mechanical point of view, cubic sample should have a minimal size of $5 \mathrm{~mm}$ side (Brown and Ferguson, 1980; Linde et al., 1991; Odgaard and Linde, 1991). 
Density measurements and mechanical elastic properties obtained in this study are in the same order as those found in the literature (Jensen et al., 1991; Lespessailles et al., 1998; Lindahl, 1976; Mitton et al., 1998). Significant correlations were found between the different parameters, as already shown for this site (Jensen et al., 1991; Langton et al., 1996; Weaver and Chalmers, 1966). Results obtained by finite hexahedral element for trabecular Young's modulus are greatly higher than those found in the literature $(E=34.2 \pm 22.83 \mathrm{GPa}, n=12)$. This result is at least 2-fold higher than values obtained in any human bone. Recently, Morgan et al. has shown that trabecular bone modulus-density relationships depend on anatomic site (Morgan et al., 2003). Those authors obtained a range of Young's modulus between 4.73, 15.01 and 15.52 GPa for, respectively. human vertebra (T10-L5), greater trochanter and proximal tibia. Van Rietbergen et al. investigated whether the calculation of cancellous bone mechanical properties from microfinite element models based on such new peripheral quantitative computed tomography (pQCT) and magnetic resonance (MR) was feasible (Van Rietbergen et al., 1995, 1998). Authors found a maximal Young's modulus equal to $2 \mathrm{GPa}$ by pQCT but did not use experimental compressive testing. More recently, Pistoia et al. used a similar technique (Pistoia et al., 2001, 2002), based on FE models to calculate elastic properties of trabecular bone in vitro. It has been demonstrated that this technique can provide an accurate prediction of anisotropic bone elastic properties (Ladd and Kinney, 1998; Van Rietbergen, 1997a, b), but none of these type of studies has been exploited on calcaneus. Recently, Crawford et al. (Crawford et al., 2003 b) built a "voxel-base" FE models of 14 excised human cadaveric lumbar vertebral body, and they used a low- and high-resolution models $(3 \times 3 \times 3 \mathrm{~mm}$ and $1 \times 1 \times 1.5 \mathrm{~mm}$ element size) and tried to mimic the experimental condition ( $E=2500 \mathrm{MPa}, v=0.3$ ) to predict the experimentally measured compressive fracture strength of the vertebral bodies. To explain the difference observed between the present numerical Young's modulus obtained by hexahedral elements and those found by all precedent authors, we suggest our models were not well adapted for each bone structure. Hexahedral elements do not well represent bending behavior, and, in case of very thin structure (like osteoporotic bone), sample bones were not only subject to compressive stress but also bending stress. Niebur et al. suggested another behavior law, with a bilinear tissue level constitutive model (Niebur et al., 2000, 2002). Numerical errors of the calculated elastic moduli are shown by Ladd et al. and depended on resolution (Ladd et al., 1998). To quantify reductions in mechanical properties, such as Young's modulus and strength in trabecular bone loss, Guo et al. used an idealized 3D microstructural model of trabecular bone to create bone loss (Guo and Kim, 2002).
We have also found that the numerical Young's modulus appears smaller using a skeleton model instead of a hexahedral model ( $E_{\text {trabecular }}^{\text {num-skelon: }} 10,305 \pm 5500 \mathrm{MPa}$, $\left.E_{\text {trabecular }}^{\text {num-hedral }}: 31,580 \pm 2700 \mathrm{MPa}\right)$, they are significantly different but there is a significant correlation between these two numerical calculations. With our skeleton model, results found reflect only a method to mimic experimental mechanical properties. Comparing the numerical to the experimental apparent Young's modulus, we did not find a relation between $E_{\text {app }}^{\text {exp }}$ and $E_{\text {trabecular }}^{\text {num-hexal }}$ showing that the overestimation of those values could not give an estimation of this experimental parameter. However, we showed that, changing the type of element, we could estimate $E_{\mathrm{app}}^{\exp }$. Moreover, there is a significant difference between each bone volume fraction (calculated by $\mu \mathrm{CT}$ and by beam volume). It can be explained by the fact that we used mean TbTh obtained by $\mu \mathrm{CT}$ to built beam FE Experimental apparent mechanical properties are strongly related to $\mathrm{BV} / \mathrm{TV}$. Between individual cube samples, using an hexahedral or beam model, the range of difference in numerical Young's modulus is from $32 \%$ for $\mathrm{BV} / \mathrm{TV}=10.75 \%$ to $82 \%$ for $\mathrm{BV} / \mathrm{TV}=5.74 \%$. These results show the effect of both the type of element used and the initial BV/TV. However, results obtained on numerical Young's modulus obtained by skeleton models are near to those found in the literature (mean: $\left.E_{\text {trabecular }}^{\text {num-skelen. }} 10,305 \pm 5500 \mathrm{MPa}\right)$. A disadvantage of this method is that we chose only bone samples with very thin trabecular bone to be able to apply a skeleton method (with"rod-like" structures). It would also be interesting to obtain variable trabecular thickness for each sample by $\mu \mathrm{CT}$ and implement it in a finite beam element model. Recently, different research teams started this kind of work (Dagan et al., 2004; Jaecques et al., 2004), and Stolken et al. started to simulate the trabecular bone failure (Stolken and Kinney, 2003). To conclude, the $5 \mathrm{~mm}$-side criterion might not be the only criterion to take into account, and we might have to take into account the specific structure of trabecular bone. Generally, trabecular bone is composed at the same time of rodlike and plate structures. It would be interesting to build a FE model using simultaneously beam and shell elements with different behavior law and a mineralization degree based on the grayscale level inside each trabecular bone (Follet et al., 2004) for a better representation of trabeculae bone.

\section{Acknowledgments}

The authors thank Philippe Falandry from CINES (Montpellier, France) for his skillful technical assistance and Charles H. Turner for scientific discussion and for reviewing the English manuscript. 


\section{Appendix}

$\begin{array}{ll}E_{\text {app }}^{\exp } & (\mathrm{MPa}) \\ \sigma_{\max , \text { app }}^{\exp } & (\mathrm{MPa}) \\ E_{\text {app }}^{\exp (x),(y) \text { or }(z)} & (\mathrm{MPa}) \\ E_{\text {trabecular }}^{\text {num }} & (\mathrm{MPa}) \\ \rightarrow E_{\text {trabecular }}^{\text {num-skelon }} & (\mathrm{MPa}) \\ \rightarrow E_{\text {trabecular }}^{\text {num-hedral }} & (\mathrm{MPa}) \\ \sigma_{\text {max }}^{\text {num app }} & (\mathrm{MPa}) \\ \rho_{\text {app }} & \left(\mathrm{g} \mathrm{cm}^{-3}\right) \\ \rho_{\text {tissue }} & \left(\mathrm{g} \mathrm{cm}^{-3}\right)\end{array}$

$\rho_{\text {app }} / \rho_{\text {tissue }}$
Experimental Apparent Young's Modulus after destructive test in the main trabecular direction $(z)$

Maximal experimental apparent stress

Experimental Apparent Young's Modulus after nondestructive test in the direction $(x),(y)$ or $(z)$

Numerical intrinsic trabecular Young's modulus after simulation, obtained for trabecular bone (MPa), 2 kinds:

Intrinsic trabecular Young's modulus after numeric simulation using beam elements Intrinsic trabecular Young's modulus after numeric simulation using hexahedral elements

Numerical maximal apparent stress after numerical simulation

Apparent density, defined as the weight of defatted specimen in air $\left(\mathrm{M}_{\text {air }}\right)$ divided by the specimen bulk volume $\left(\mathrm{V}_{\text {specimen }}\right)$

Tissue density, defined as the weight of defatted and dried specimen in air $\left(\mathrm{M}_{\mathrm{air}}\right)$, divided by bone volume $\left(\mathrm{V}_{\text {bulk }}\right) \rho_{\text {tissue }}=\mathrm{M}_{\text {air }} /\left(\mathrm{M}_{\mathrm{air}}-\mathrm{M}_{\text {water }}\right)$ Bone Volume estimated by Archimedes principle

\section{References}

Ashman, R.B., Cowin, S.C., Van Buskirk, W.C., Rice, J.C., 1984. A continuous wave technique for the measurement of the elastic properties of cortical bone. Journal of Biomechanics 17 (5), 349-361.

ASTM, 1992. Tangent modulus, and chord modulus. Designation E11182. In: Standard Test Method for Young's Modulus. ASTM, Philadelphia, pp. 288-293.

Brown, T.D., Ferguson Jr., A.B., 1980. Mechanical property distributions in the cancellous bone of the human proximal femur. Acta Orthopaedica Scandinavica 51 (3), 429-437.

Cendre, E., Mitton, D., Roux, J.P., Arlot, M.E., Duboeuf, F., BurtPichat, B., Rumelhart, C., Peix, G., Meunier, P.J., 1999. Highresolution computed tomography for architectural characterization of human lumbar cancellous bone: relationships with histomorphometry and biomechanics. Osteoporosis International 10 (5), 353-360.

Compston, J.E., Garrahan, N.J., Croucher, P.I., Wright, C.D., Yamaguchi, K., 1993. Quantitative analysis of trabecular bone structure. Bone 14 (3), 187-192.

Cowin, S.C., 1985. The relationship between the elasticity tensor and the fabric tensor. Mechanics of Materials 4, 137-147.

Crawford, R.P., Cann, C.E., Keaveny, T.M., 2003a. Finite element models predict in vitro vertebral body compressive strength better than quantitative computed tomography. Bone 33 (4), 744-750.

Crawford, R.P., Rosenberg, W.S., Keaveny, T.M., 2003b. Quantitative computed tomography-based finite element models of the human lumbar vertebral body: effect of element size on stiffness, damage, and fracture strength predictions. Journal of Biomechanical Engineering 125 (4), 434-438.

Dagan, D., Be'ery, M., Gefen, A., 2004. Single-trabecula building block for large-scale finite element models of cancellous bone. Medical and Biological Engineering and Computing 42 (4), 549-556.

Follet, H., Boivin, G., Rumelhart, C., Meunier, P.J., 2004. The degree of mineralization is a determinant of bone strength: a study on human calcanei. Bone 34 (5), 783-789.

Follet, H., Bruyere-Garnier, K., Peyrin, F., Roux, J.P., Arlot, M.E., BurtPichat, B., Rumelhart, C., Meunier, P.J., 2005. Relationship between compressive properties of human os calcis cancellous bone and microarchitecture assessed from $2 \mathrm{~d}$ and $3 \mathrm{~d}$ synchrotron microtomography. Bone 36 (2), 340-351.
Gefen, A., Seliktar, R., 2004. Comparison of the trabecular architecture and the isostatic stress flow in the human calcaneus. Medical and Engineering Physics 26 (2), 119-129.

Goulet, R.W., Goldstein, S.A., Ciarelli, M.J., Kuhn, J.L., Brown, M.B., Feldkamp, L.A., 1994. The relationship between the structural and orthogonal compressive properties of trabecular bone. Journal of Biomechanics 27 (4), 375-389.

Guo, X.E., Kim, C.H., 2002. Mechanical consequence of trabecular bone loss and its treatment: a three-dimensional model simulation. Bone 30 (2), 404-411.

Hollister, S.J., Brennan, J.M., Kikuchi, N., 1994. A homogenization sampling procedure for calculating trabecular bone effective stiffness and tissue level stress. Journal of Biomechanics 27 (4), 433-444.

Jaecques, S.V., Van Oosterwyck, H., Muraru, L., Van Cleynenbreugel, T., De Smet, E., Wevers, M., Naert, I., Vander Sloten, J., 2004. Individualised, micro CT-based finite element modelling as a tool for biomechanical analysis related to tissue engineering of bone. Biomaterials 25 (9), 1683-1696.

Jensen, N.C., Madsen, L.P., Linde, F., 1991. Topographical distribution of trabecular bone strength in the human os calcanei. Journal of Biomechanics 24 (1), 49-55.

Kapandji, I.A., 1994. Physiologie articulaire : schémas commentés de mécanique humaine. Tronc et rachis: le rachis dans son ensemble, la ceinture pelvienne et les articulations sacro-iliaques, le rachis lombaire, le rachis dorsal et la respiration, le rachis cervical, 5ème édition. ed., vol. 3. Ed. Maloine, Paris, p. 255.

Keaveny, T.M., Borchers, R.E., Gibson, L.J., Hayes, W.C., 1993. Trabecular bone modulus and strength can depend on specimen geometry. Journal of Biomechanics 26 (8), 991-1000.

Keaveny, T.M., Morgan, E.F., Niebur, G.L., Yeh, O.C., 2001. Biomechanics of trabecular bone. Annual Review of Biomedical Engineering 3, 307-333.

Kopperdahl, D.L., Morgan, E.F., Keaveny, T.M., 2002. Quantitative computed tomography estimates of the mechanical properties of human vertebral trabecular bone. Journal of Orthopaedic Research 20 (4), 801-805.

Ladd, A.J., Kinney, J.H., 1998. Numerical errors and uncertainties in finite-element modeling of trabecular bone. Journal of Biomechanics 31 (10), 941-945.

Ladd, A.J., Kinney, J.H., Haupt, D.L., Goldstein, S.A., 1998. Finiteelement modeling of trabecular bone: comparison with mechanical 
testing and determination of tissue modulus. Journal of Orthopaedic Research 16 (5), 622-628.

Langton, C.M., Njeh, C.F., Hodgskinson, R., Currey, J.D., 1996. Prediction of mechanical properties of the human calcaneus by broadband ultrasonic attenuation. Bone 18 (6), 495-503.

Lee, T.C., Kashyap, R.L., Chu, C.N., 1994. Building skeleton models via 3-D medial surface axis thinning algorithms. Cvgip-Graphical Models and Image Processing 56 (6), 462-478.

Lespessailles, E., Jullien, A., Eynard, E., Harba, R., Jacquet, G., Ildefonse, J.P., Ohley, W., Benhamou, C.L., 1998. Biomechanical properties of human os calcanei: relationships with bone density and fractal evaluation of bone microarchitecture. Journal of Biomechanics 31 (9), 817-824.

Lindahl, O., 1976. Mechanical properties of dried defatted spongy bone. Acta Orthopaedica Scandinavica 47 (1), 11-19.

Linde, F., Norgaard, P., Hvid, I., Odgaard, A., Soballe, K., 1991. Mechanical properties of trabecular bone. Dependency on strain rate. Journal of Biomechanics 24 (9), 803-809.

Mitton, D., Cendre, E., Roux, J.P., Arlot, M.E., Peix, G., Rumelhart, C., Babot, D., Meunier, P.J., 1998. Mechanical properties of ewe vertebral cancellous bone compared with histomorphometry and high-resolution computed tomography parameters. Bone 22 (6), 651-658.

Morgan, E.F., Bayraktar, H.H., Keaveny, T.M., 2003. Trabecular bone modulus-density relationships depend on anatomic site. Journal of Biomechanics 36 (7), 897-904.

Niebur, G.L., Feldstein, M.J., Yuen, J.C., Chen, T.J., Keaveny, T.M., 2000. High-resolution finite element models with tissue strength asymmetry accurately predict failure of trabecular bone. Journal of Biomechanics 33 (12), 1575-1583.

Niebur, G.L., Yuen, J.C., Burghardt, A.J., Keaveny, T.M., 2001. Sensitivity of damage predictions to tissue level yield properties and apparent loading conditions. Journal of Biomechanics 34 (5), 699-706.

Niebur, G.L., Feldstein, M.J., Keaveny, T.M., 2002. Biaxial failure behavior of bovine tibial trabecular bone. Journal of Biomechanical Engineering 124 (6), 699-705.

Odgaard, A., Linde, F., 1991. The underestimation of Young's modulus in compressive testing of cancellous bone specimens. Journal of Biomechanics 24 (8), 691-698.

Peyrin, F., Salome, M., Cloetens, P., Laval-Jeantet, A.M., Ritman, E., Ruegsegger, P., 1998. Micro-CT examinations of trabecular bone samples at different resolutions: 14, 7 and 2 micron level. Technology and Health Care 6 (5-6), 391-401.

Peyrin, F., Salome, M., Nuzzo, S., Cloetens, P., Laval-Jeantet, A.M., Baruchel, J., 2000. Perspectives in three-dimensional analysis of bone samples using synchrotron radiation microtomography. Cell and Molecular Biology (Noisy-le-grand) 46 (6), 1089-1102.

Pistoia, W., van Rietbergen, B., Laib, A., Ruegsegger, P., 2001. Highresolution three-dimensional-pQCT images can be an adequate basis for in-vivo microFE analysis of bone. Journal of Biomechanical Engineering 123 (2), 176-183.
Pistoia, W., van Rietbergen, B., Lochmuller, E.M., Lill, C.A., Eckstein, F., Ruegsegger, P., 2002. Estimation of distal radius failure load with micro-finite element analysis models based on three-dimensional peripheral quantitative computed tomography images. Bone 30 (6), 842-848.

Putz, R., Pabst, R.J. S., 1994. Atlas d'anatomie humaine. Medicales Internationales ed. (Ed.), vol. 1, Paris, 416pp.

Salome, M., Peyrin, F., Cloetens, P., Odet, C., Laval-Jeantet, A.M., Baruchel, J., Spanne, P., 1999. A synchrotron radiation microtomography system for the analysis of trabecular bone samples. Medical Physics 26 (10), 2194-2204.

Simmons, C.A., Hipp, J.A., 1997. Method-based differences in the automated analysis of the three-dimensional morphology of trabecular bone. Journal of Bone and Mineral Research 12 (6), 942-947.

Stolken, J.S., Kinney, J.H., 2003. On the importance of geometric nonlinearity in finite-element simulations of trabecular bone failure. Bone 33 (4), 494-504.

Thovert, J.F., Salles, J., Adler, P.M., 1993. Computerized characterization of the geometry of real porous media - their discretization, analysis and interpretation. Journal of Microscopy-Oxford 170, 65-79.

Turner, C.H., Cowin, S.C., Rho, J.Y., Ashman, R.B., Rice, J.C., 1990. The fabric dependence of the orthotropic elastic constants of cancellous bone. Journal of Biomechanics 23 (6), 549-561.

Van Rietbergen, B., Weinans, H., Huiskes, R., Odgaard, A., 1995. A new method to determine trabecular bone elastic properties and loading using micromechanical finite-element models. Journal of Biomechanics 28 (1), 69-81.

Van Rietbergen, B., Weinans, H., Polman, B.J.W., Huiskes, R., 1996. Computational strategies for iterative solutions of large FEM applications employing voxel data. International Journal of Numerical Methods in Engineering 39 (2743-2767).

Van Rietbergen, B., Kabel, J., Odgaard, A., Huiskes, R., 1997a. Determination of trabecular bone tissue elastic properties by comparison of experimental and finite element results. In: Oomens, H.S.A.C.W.J. (Ed.), Material Identification Using Mixed Numerical Experimental Methods. Kluwer Academic Publishers, Dordrecht, The Netherlands.

Van Rietbergen, B., Weinans, H., Huiskes, R., 1997b. Prospects of computer models for the prediction of osteoporotic bone fracture risk. Studies in Health Technology and Informatics 40, 25-32.

Van Rietbergen, B., Majumdar, S., Pistoia, W., Newitt, D.C., Kothari, M., Laib, A., Ruegsegger, P., 1998. Assessment of cancellous bone mechanical properties from micro-FE models based on micro-CT, pQCT and MR images. Technology and Health Care 6 (5-6), 413-420.

Weaver, J.K., Chalmers, J., 1966. Cancellous bone: its strength and changes with aging and an evaluation of some methods for measuring its mineral content. Journal of Bone and Joint Surgery-American Volume 48 (2), 289-298.

Yeh, O.C., Keaveny, T.M., 1999. Biomechanical effects of intraspecimen variations in trabecular architecture: a three-dimensional finite element study. Bone 25 (2), 223-228. 